\title{
A parametric study on the emissions from an HCCI alternative combustion engine resulting from the auto-ignition of Primary Reference Fuels
}

\author{
Hatim Machrafi*, Simeon Cavadias, Jacques Amouroux \\ UPMC Université Paris 06, LGPPTS, Ecole Nationale Supérieure de Chimie de Paris, 11, rue de Pierre et Marie \\ Curie, 75005 Paris, France \\ Tel.: +331442767 18; Fax: +33143265813
}

\begin{abstract}
The Homogeneous Charge Compression Ignition is an alternative combustion technology that can reduce automobile pollution, provided that the exhaust emission can be controlled. A parametric study can be useful in order to gain more understanding in the emission reduction possibilities via this new combustion technology. For this purpose, the inlet temperature, the equivalence ratio and the compression ratio are changed respectively from 30 to $70{ }^{\circ} \mathrm{C}, 0.28$ to 0.41 and 6 to 14. Also the diluting, thermal and chemical effects of Exhaust Gas Recirculation were studied. The emission of $\mathrm{CO}, \mathrm{CO}_{2}, \mathrm{O}_{2}$ and hydrocarbons has been measured using Primary Reference Fuels. It appears that an increase in the inlet temperature, the EGR temperature, the equivalence ratio and the compression ratio results into a decrease of the emissions of $\mathrm{CO}$ and the hydrocarbons of up to $75 \%$. The emission of $\mathrm{CO}_{2}$ increased, however, by $50 \%$. The chemical parameters showed more complicated effects, resulting into a decrease or increase of the emissions, depending on whether the overall reactivity increased or not. If the reactivity increased, generally, the emissions of $\mathrm{CO}$ and hydrocarbons increased, while that of $\mathrm{CO}_{2}$ increased. The increase of $\mathrm{CO}_{2}$ emissions could be compensated by altering the compression ratio and the EGR parameters, making it possible to control the emission of the HCCI engine.
\end{abstract}

Key words: Alternative combustion, pollution reduction, emission characteristics, HCCI 


\section{Introduction}

In previous work [1], the HCCI mode of combustion is presented as an interesting alternative for the reduction of emissions from conventional engines. A definition of this mode of combustion is made and several advantages and disadvantages are discussed. Several work [27] is performed, presenting stable HCCI combustion with many different fuels (e.g. hydrogen, natural gas, gasoline and diesel oil). Often, it concerned the analysis of auto-ignition phenomena and global entities. Other work is related to emission reduction from conventional engines [8-14]. Of these fuels, gasoline and diesel are mostly used for terrestrial transport nowadays. For optimal functioning purposes and engine damage preventing, these fuels have to meet some severe quality requirements, especially when it concerns the emission of harmful gases in the atmosphere. Whilst much research is performed on stable HCCI combustion and on emission reduction from conventional engines, as mentioned earlier in the text, not much research is performed about emission reduction from an HCCI engine [15-17], let alone a wide parametric study. It is true that the major problem, which stands in the way of implementing the HCCI combustion, is its control and the possible high emissions of hydrocarbons and $\mathrm{CO}$. It has been noted that on increasing or decreasing the equivalence ratio (too lean or too rich mixtures), the $\mathrm{HC}$ emissions would rise, since combustion becomes highly incomplete, either by a lack of fuel or by a lack of oxygen. This is one of the major problems of the implentation of the HCCI engine, since it runs on a lean mixture. Also, the most important parameter that affects $\mathrm{CO}$ emission and its conversion to $\mathrm{CO}_{2}$, is the fuel-air equivalence ratio. As is said before, not much research is performed specifically on the emissions coming from an HCCI engine. Moreover, the optimal operating range of an HCCI engine is still under discussion. Therefore, a better understanding is required of how the emissions of a certain HCCI engine are influenced by several operating and design parameters. 
The purpose of this paper is to investigate the trends of the emissions of $\mathrm{CO}, \mathrm{CO}_{2}$ and total hydrocarbons at the exhaust of an HCCI engine by changing the inlet temperature from 30 to $70{ }^{\circ} \mathrm{C}$, the equivalence ratio from 0.28 to 0.41 , the compression ratio from 6 to 14 , the EGR dilution $\left(\mathrm{N}_{2}\right)$ from 0 to $47 \mathrm{vol} \%$, the EGR temperature from 30 to $110{ }^{\circ} \mathrm{C}$ and the concentration of some chemically active species, present in EGR. The concentrations of CO and $\mathrm{NO}$ are altered from 0 to $160 \mathrm{ppm}$ and that of $\mathrm{CH}_{2} \mathrm{O}$ from 0 to $1400 \mathrm{ppm}$. These three species are chosen since they cover some of the most important pollutants in the exhaust gases. The exhaust gases can be used to control the auto-ignition. This could influence the emission and therefore it is interesting to investigate how EGR can influence the emission from an HCCI engine. The fuel-type, being the source of the pollution, is included into the parameters to be used. Mixtures of n-heptane and iso-octane are used varying iso-octane from 0 to 100 vol\%. These fuels are called the Primary Reference Fuels and are fuels of which much is known. Therefore, a study as this one should start with fuels that are known, in order to focus on the effect of the aforementioned parameters on the emissions of an HCCI engine. The emission of $\mathrm{O}_{2}$ is discussed along with the three mentioned earlier, since it is a measure of the completeness of the reaction. If, for instance, the hydrocarbon emissions show no decrease, while the oxygen emission does, this suggests that the hydrocarbons have not been burned, but instead transformed into oxygenated compounds. The emissions are represented in iso-quantities unless mentioned otherwise.

\section{Experimental set-up}

Apparently, many parameters can be used to study how the control of the emissions can be achieved. It is needless to say that the control of the auto-ignition of this type of engine goes hand in hand with its efficiency and its exhaust gases, since operating at certain conditions 
with high efficiency but high emissions is clearly not the purpose. It is thus of great importance to determine the behaviour of some important emissions when altering some parameters in the quest of controlling the auto-ignition of a certain HCCI engine. The measuring equipment that is used for this study is the same as put out in previous work [1]. The HCCI engine used for this study is a water-cooled mono-cylinder CFR (Cooperative Fuel Research) engine, having a displacement volume of $611 \mathrm{~cm}^{3}$, a bore of $82.55 \mathrm{~mm}$ and a stroke of $114.5 \mathrm{~mm}$. The compression is variable from 4 to 16 , by changing the position of the cylinder head. The ratio of the connecting rod to the crank radius is 4.44 . The exhaust valve opens at $140^{\circ} \mathrm{ATDC}$ and closes at $15^{\circ} \mathrm{ATDC}$, while the intake valve opens at $10^{\circ} \mathrm{ATDC}$ and closes at $146{ }^{\circ} \mathrm{BTDC}$. The lean air-fuel mixture is premixed in a mixture tank, where the fuel flow, the air flow, the temperature and the pressure can be measured and regulated at the same time. The EGR composition is prepared in an EGR mixing tank. The diluting and chemically active species are provided from pressurized bottles. Before they enter the EGR tank, the flow is regulated, determining thereby the composition of the EGR. Once mixed, the EGR composition leaves the EGR tank and passes through a heat exchanger and a flow meter before entering the mixture tank with the air and fuel. By means of the heat exchanger and the flow meter, the EGR temperature and flow are regulated before being mixed with the air/fuel mixture. During the experiments, the oil temperature is set at $40{ }^{\circ} \mathrm{C}$ and the cooling water temperature at $50{ }^{\circ} \mathrm{C}$. The gas analysis is performed by a COSMA analyser. The exhaust gas that leaves the engine is pushed by the exhaust stroke into the exhaust pipe and lead towards the gas analyser. The measurements were repeated three times at the same operating conditions. All the measured gases' concentrations had a standard deviation of $2 \%$. The detection limit of the measurement of the $\mathrm{HC}$ is $100 \mathrm{ppm}$, that of $\mathrm{CO}$ and $\mathrm{CO}_{2}$ is $0,1 \%$ and that of $\mathrm{O}_{2}$ is $1 \%$. The oxygen fraction is determined using a paramagnetic oxygen analyser (Cosma Cristal 300). $\mathrm{CO}$ and $\mathrm{CO}_{2}$ are analyzed by infra red absorption by a Cosma Beryl 100 
apparatus. The absorption wavelength of $\mathrm{CO}_{2}$ is $2300-2400 \mathrm{~cm}^{-1}$ and of $\mathrm{CO}$ it is $2100-2300$ $\mathrm{cm}^{-1}$. The hydrocarbons are analyzed by flame ionization detection by a Cosma graphite 55 apparatus.

\section{Results and discussion: influence of the physical and mechanical parameters}

First of all, it is worth mentioning that, within a detection limit of 10 ppmv, no $\mathrm{NO}_{\mathrm{x}}$ is measured in the exhaust of the HCCI engine at the experimental conditions of this paper. Figure 1 presents the first results. Note that in figure 1, the fuel composition is presented as the $n$-heptane content in an n-heptane/iso-octane mixture. So the value 60 means that there is a $60 \mathrm{vol} \% \mathrm{n}$-heptane in the mixture and thus $40 \mathrm{vol} \%$ iso-octane, also called a PRF40. Unless the fuel is the parameter itself, all the experiments were performed with the fuel PRF40. The compression ratio and the inlet temperature are at all times respectively 10.2 and $70{ }^{\circ} \mathrm{C}$, unless they are used as parameters. The engine speed is $600 \mathrm{rpm}$. The equivalence ratio is always used as a parameter.

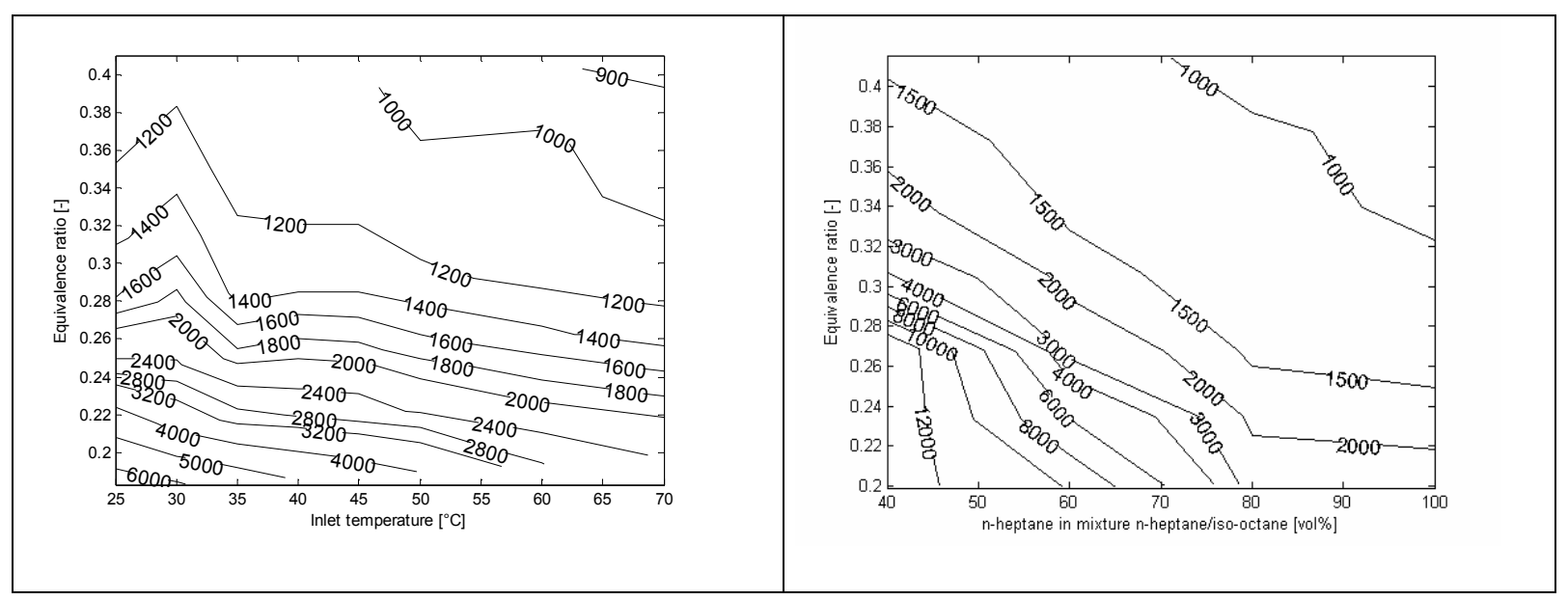




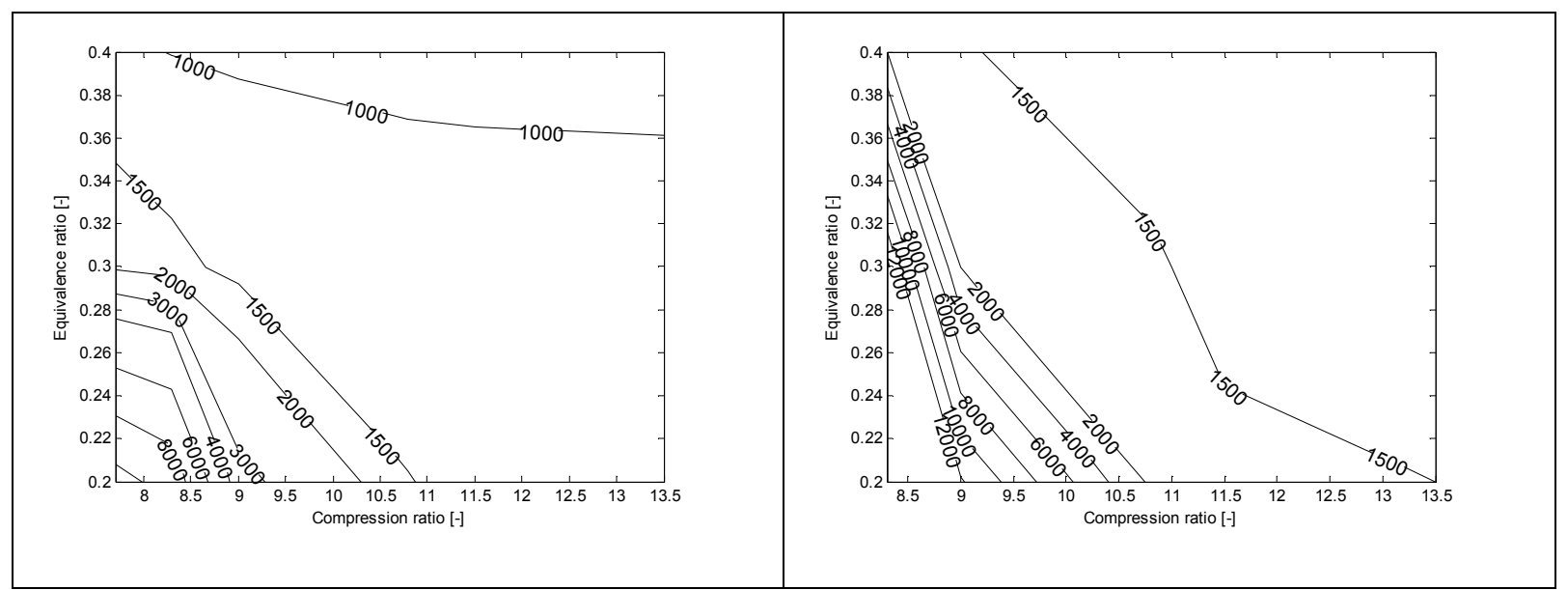

Figure 1: Iso-emissions for the hydrocarbons as a function of the inlet temperature, the equivalence ratio, the fuel composition and the compression ratio for $n$-heptane. The figure at the bottom-right is with 60 vol\% n-heptane and 40 vol\% iso-octane

Figure 1 shows that a higher temperature and equivalence ratio result into a lower $\mathrm{HC}$ emission, because both parameters increase the overall reactivity. It appears that the influence of the inlet temperature seems to be much more significant at lower equivalence ratios, probably because of the incomplete combustion at lower equivalence ratios. More importantly, the higher equivalence radio increases the specific heat capacity of the mixture, which leads to less sensitivity to the inlet temperature. The lower hydrocarbon emissions, despite the presence of more fuel, may be due to different factors [15]. The higher equivalence ratio mixture causes more rapid pressure rise during the auto ignition process, resulting in higher temperatures that promote ignition and thus more fuel is burned. The hydrocarbon reduction at higher equivalence ratios also may result from late hydrocarbon oxidation during the expansion stroke, also due to the higher overall temperature caused by the greater heat release at higher temperatures. The lower hydrocarbon emissions at higher inlet temperatures could be explained that a higher temperature at the expansion is attained enhancing the hydrocarbons oxidation, lowering the hydrocarbon emissions. Concerning HC emissions, similar results have been obtained by Flowers and al. [15] with different fuels: 
propane and DME/methane blend, but with higher inlet temperature $\left(130{ }^{\circ} \mathrm{C}-170{ }^{\circ} \mathrm{C}\right)$. The emissions of the hydrocarbons decrease when the compression ratio is increased. A higher compression ratio increases the overall molar concentrations and the peak temperature. This increases the overall reactivity. Therefore more hydrocarbons are burned or oxidized and less hydrocarbon emission is observed. Addition of iso-octane seems to increase the emission of hydrocarbons. During the combustion process of iso-octane, more stable intermediary species (such as olefins) are formed than for n-heptane, which delay the final ignition. As a result of this, the later final ignition could leave less time for the hydrocarbons to burn and result into a higher hydrocarbon emission when adding iso-octane to n-heptane. Finally, it could be said that the hydrocarbons emissions can be reduced up to 4 times, with only doubling, for instance, the equivalence ratio or the inlet temperature. The results concerning oxygen reflect the same patterns as for the hydrocarbons and therefore the results are not presented. The consummation of oxygen goes parallel with the consummation of the hydrocarbons, except at the transition from incomplete combustion to complete combustion. Before this transition, oxygen may react, but merely oxidizes the hydrocarbons and thus not converting them. After this transition, both oxygen and the hydrocarbons react and the trends are the same. This transition also takes place in the case of the emissions of $\mathrm{CO}$, as shown in figure 2. Before these results are presented, it should be noted that in the crevice region in the cylinder, the hydrocarbon content tends to be higher than in the rest of the cylinder, due to the colder cylinder wall (engine cooling). This means that the emissions in the cylinder are not entirely homogeneous as the temperature is not entirely homogeneous in the cylinder. This also influences the emission of CO. Nonetheless, the allure of the iso-maps does not change and the same conclusions can be drawn. 


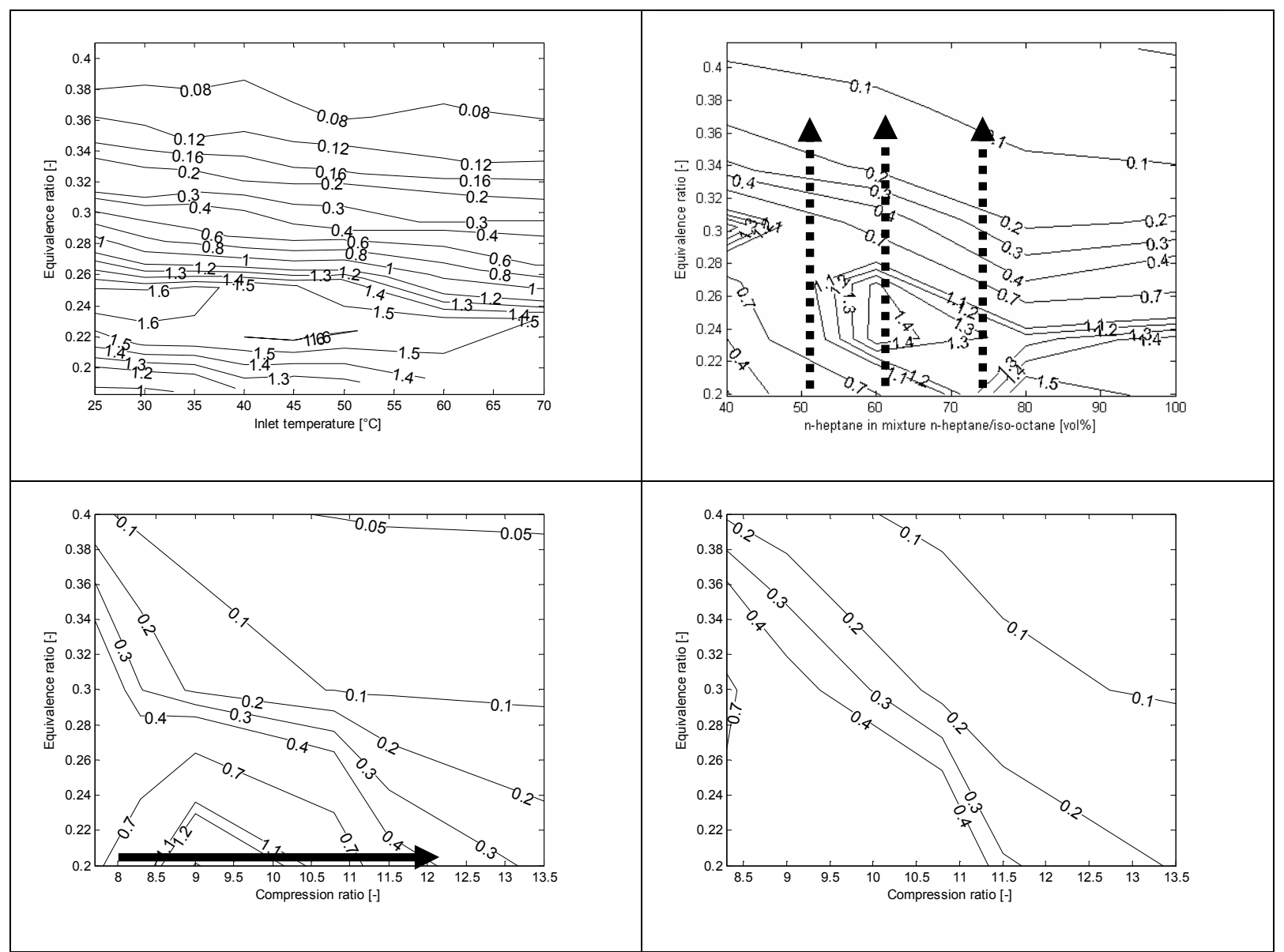

Figure 2: Iso-emissions for CO as a function of the inlet temperature, the equivalence ratio, the fuel composition and the compression ratio for $n$-heptane. The figure at the bottom-right is with 60 vol\% n-heptane and 40 vol\% iso-octane

From figure 2 it seems that the inlet temperature does not influence significantly the emission of $\mathrm{CO}$, while the equivalence ratio influences a lot. The influence of the equivalence ratio can be illustrated further by figure 3. Figure 3 shows that the influence of the equivalence ratio on the $\mathrm{CO}$ emission can be categorised into four parts, related with the indicated efficiency. At an equivalence ratio around 0.2 an increase of the equivalence ratio increases the $\mathrm{CO}$ production. At an equivalence ratio around 0.25 no significant influence is observed. At an equivalence ratio between 0.25 and 0.3 an increase of the equivalence ratio results onto a lower $\mathrm{CO}$ production, whereas at equivalence ratios higher than 0.35 again no influence is observed, having very low $\mathrm{CO}$ concentrations in the exhaust. 


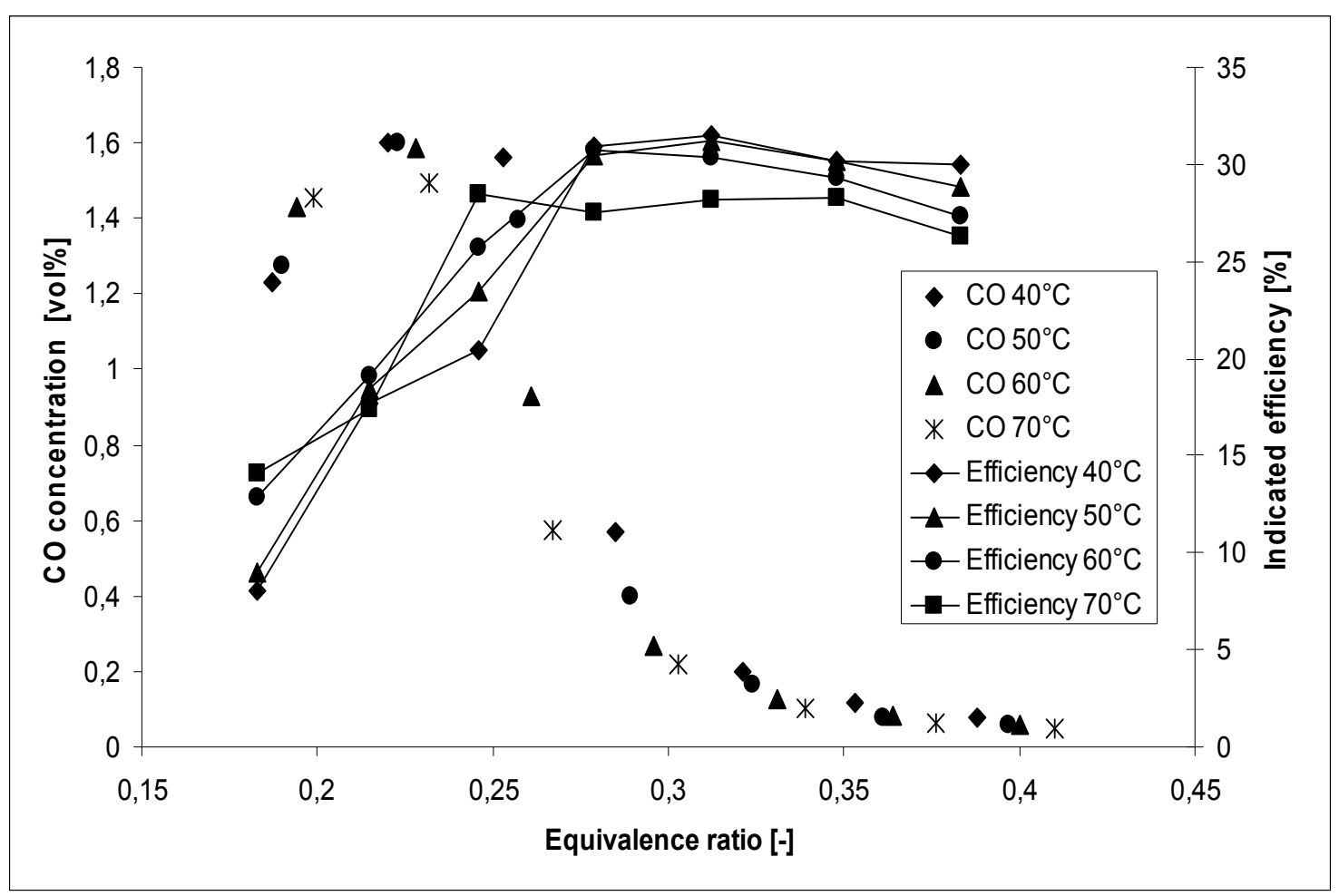

Figure 3: CO emissions and indicated efficiency as a function of the inlet temperature and the equivalence ratio with a compression ratio of 10.2 and PRF40 as the fuel

The CO emissions, resulted from HCCI combustion are primarily controlled by the fuel/air ratio. This and the results obtained are in good agreement with which Lü et al. [16,17] observed. Chemical kinetics are essential to the formation and consumption of $\mathrm{CO}$. $\mathrm{CO}$ is a result of incomplete combustion in the intermediary temperature zone $(700<\mathrm{T}<900 \mathrm{~K})$ where the $\mathrm{OH}$ radicals' concentration is low [18]:

$\mathrm{O}=\mathrm{ROOH}+$ olefin $\rightarrow \mathrm{H}_{2} \mathrm{O}+\mathrm{CO}$ (irreversible)

Finally $\mathrm{CO}$ is converted at very high temperatures by the following reaction:

$\mathrm{CO}+\mathrm{OH} \rightarrow \mathrm{CO}_{2}+\mathrm{H}$

This reaction is responsible of the conversion of $\mathrm{CO}$ in $\mathrm{CO} 2$. 
It can be seen that a reasonable indicated efficiency (around $30 \%$ ) is attained around an equivalence ratio of 0.25 . It is a question of kinetics. If the indicated efficiency is too low (at lower equivalence ratios), there are not enough $\mathrm{OH}$ radicals, nor is the temperature high enough in order for $\mathrm{CO}$ to be converted into $\mathrm{CO}_{2}$. A higher equivalence ratio results then into more fuel, more peroxides, more aldehydes and consequently more $\mathrm{CO}$. As soon as the equivalence ratio is high enough and also the indicated efficiency, a great part of the fuel will be consumed by $\mathrm{OH}$ and thus the reaction of $\mathrm{CO}$ and $\mathrm{OH}$ becomes more important. This results into more $\mathrm{CO}_{2}$ and less $\mathrm{CO}$ in the exhaust. From that moment, a higher equivalence ratio will decrease the amount of $\mathrm{CO}$ and increase the amount of $\mathrm{CO}_{2}$ at the exhaust. These observations are illustrated in figure 2 for several fuel compositions, indicated by dotted arrows. N-heptane seems to be the exception. This can be explained by the high reactivity of n-heptane, causing the conversion of $\mathrm{CO}$ to $\mathrm{CO}_{2}$ at even the lower equivalence ratios.

Figure 2 shows that the influence of the compression ratio follows the same principle as that of the equivalence ratio, but in an indirect way. That is, an increasing compression ratio increases the overall molar concentrations and the gas temperature in the cylinder. This makes the overall reactivity increase. At lower compression ratios, the fuel is partially oxidized and more $\mathrm{CO}$ is found in the exhaust. At higher compression ratios, the gas temperature and overall reactivity is higher, making more $\mathrm{CO}$ convert into $\mathrm{CO}_{2}$. This is indicated by a horizontal arrow in figure 2. An addition of iso-octane to the mixture seems to increase the $\mathrm{CO}$ emissions, since iso-octane simply contains more carbon atoms, but also because the reactions that convert $\mathrm{CO}$ into $\mathrm{CO}_{2}$ occur later for iso-octane than for $\mathrm{n}$-heptane, due to the former's lower reactivity. The influence of the fuel composition on the emission of $\mathrm{CO}_{2}$ is, however, more complicated. This can be explained better by observing the results presented in the top-right diagram in figure 4. 


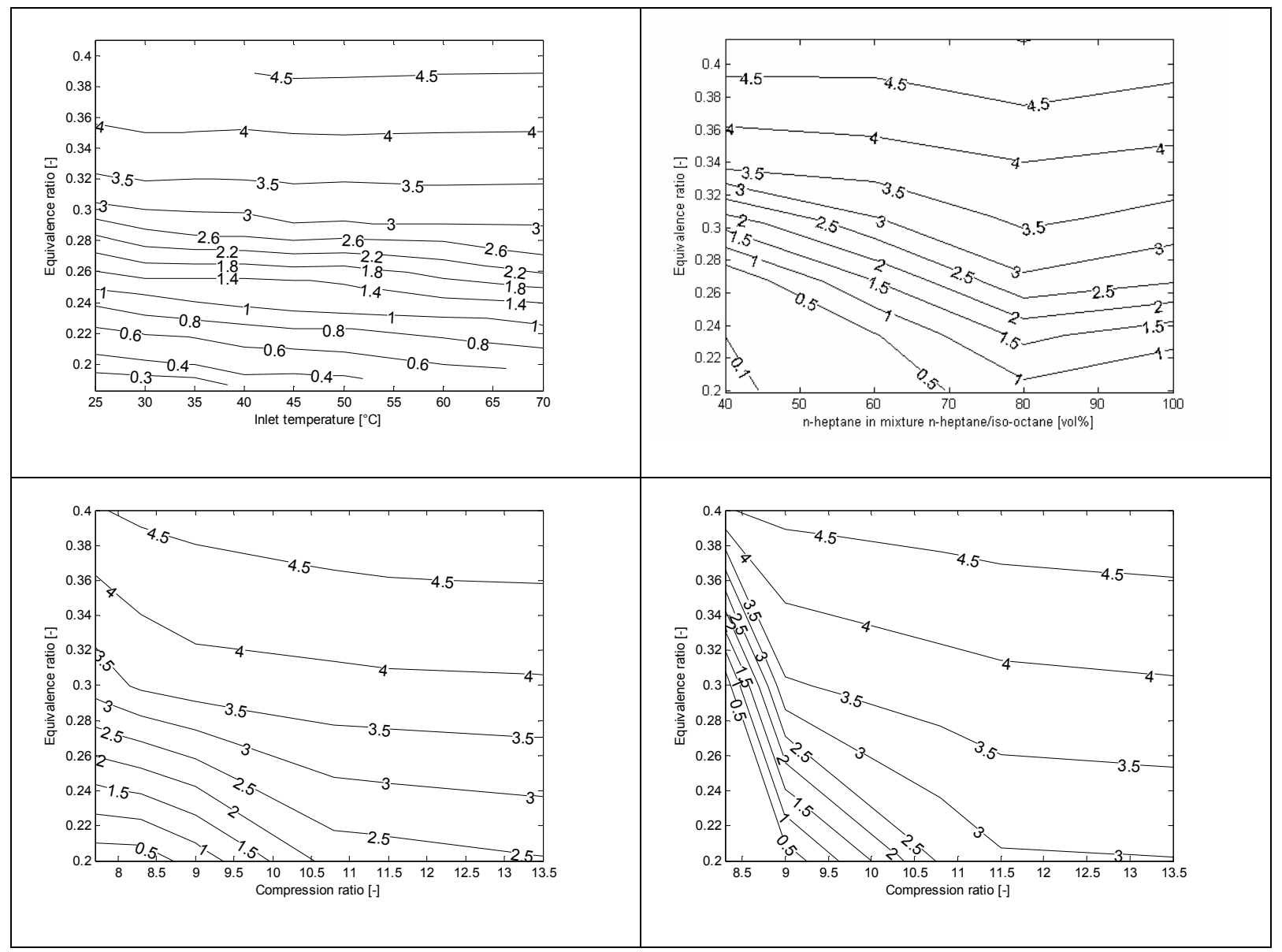

Figure 4: Iso-emissions for $\mathrm{CO}_{2}$ as a function of the inlet temperature, the equivalence ratio, the fuel composition and the compression ratio for $n$-heptane. The figure at the bottom-right is with 60 vol\% n-heptane and 40 vol\% iso-octane

Figure 4 shows that the inlet temperature does not seem to influence the emission of $\mathrm{CO}_{2}$, since it only speeds up the kinetics at complete combustion. An addition of iso-octane to the mixture increases slightly the $\mathrm{CO}_{2}$ emission and then decreases it. Two different phenomena can play an important role. The first one is presented by the following reaction:

$\mathrm{C}_{a} \mathrm{H}_{b}+\frac{1}{\varphi}\left(a+\frac{b}{4}\right)\left(\mathrm{O}_{2}+3.76 \mathrm{~N}_{2}\right) \rightarrow a \mathrm{CO}_{2}+\frac{b}{2} \mathrm{H}_{2} \mathrm{O}+d \mathrm{~N}_{2}+e \mathrm{O}_{2}$

This reaction shows clearly that a fuel containing more carbon atoms, such as iso-octane with respect to $n$-heptane, produces more $\mathrm{CO}_{2}$ when ignited. The second phenomenon is that 
adding iso-octane to n-heptane lowers the overall reactivity. Depending on what aspect is the most important one, the $\mathrm{CO}_{2}$ concentration decreases or increases for a fuel containing more iso-octane. The reaction above also shows clearly that a higher equivalence ratio $(\phi)$ results into more $\mathrm{CO}_{2}$. Figure 4 shows furthermore that increasing the compression ratio at lower compression ratios increases the amount of $\mathrm{CO}_{2}$, since at that moment the compression is not enough to have a complete combustion. At higher compression ratios, the combustion is complete and no significant influence is observed.

Note that at higher equivalence ratios, compression ratios the gas peak temperature can be that high that $\mathrm{NO}_{\mathrm{x}}$ can be formed in the emission of the HCCI engine. In that case it would be important to discuss the emissions of hydrocarbons and $\mathrm{CO}$ along with the emission of $\mathrm{NO}_{\mathrm{x}}$.

\section{Results and discussion: influence of EGR parameters}

\subsection{The influence of the dilution aspect of EGR}

The influence of the dilution by $\mathrm{N}_{2}$ on the emissions $\left(\mathrm{CO}_{2}, \mathrm{CO}\right.$ and hydrocarbons), showed clear trends that need no illustration. Therefore the figures are not presented but some comments are made on the findings. It appears that the dilution increases the emission of hydrocarbons. The dilution lowers the oxygen content, so that the amount of fuel that can be burned is less and more hydrocarbons are unburned and appear in the emission. Moreover, the higher dilution results into a lower peak temperature, leaving less time and energy for the hydrocarbons to burn. The $\mathrm{CO}$ emissions seem to increase slightly when increasing the dilution. A higher dilution decreases the peak temperature, as said before, and incomplete combustion can take place when the dilution is too strong, increasing the CO concentration. At low equivalence ratios, the indicated efficiency is relatively low. So increasing the dilution will make the combustion more incomplete, increasing the $\mathrm{CO}$ concentration. Moreover, it seemed also that the emission of $\mathrm{CO}_{2}$ decreases slightly when the dilution increases. The 
dilution entrains a lower peak temperature and lowers the burn rate, burning fewer hydrocarbons and producing thus less $\mathrm{CO}_{2}$. The effect of dilution by $\mathrm{CO}_{2}$ is the same as for $\mathrm{N}_{2}$ and will therefore not be presented. The major difference is that the effect is stronger for $\mathrm{CO}_{2}$, due to its higher heat capacity.

\subsection{The emissions regarding EGR chemical additives}

The chemical species CO did not show any influence and nor did the EGR temperature at the specified investigated ranges. Therefore no use can be found in displaying the effects of CO and the EGR temperature on the emissions. Two other species are observed next, respectively $\mathrm{NO}$ and $\mathrm{CH}_{2} \mathrm{O}$. The species' concentrations are regulated by their fraction in the EGR and by the EGR ratio. The EGR ratio that is used is $23 \mathrm{vol} \%$ at a temperature of $70{ }^{\circ} \mathrm{C}$, in order to cancel out any intervening of the EGR temperature. A higher EGR ratio would introduce too much dilution and would thus shadow the effect of the chemical species. A lower EGR ratio would not allow for the desired concentrations of the chemical species to be attained. The effect of NO on the emissions for the fuel PRF40 is presented in figure 5.

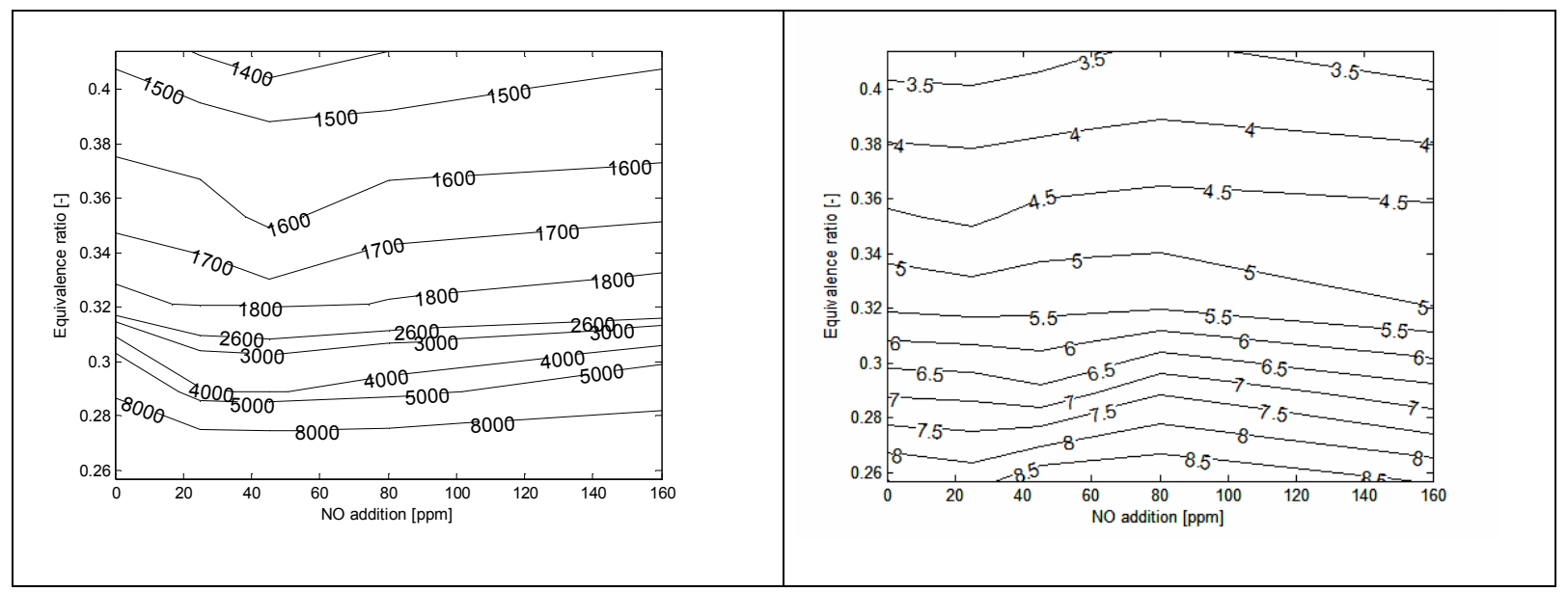




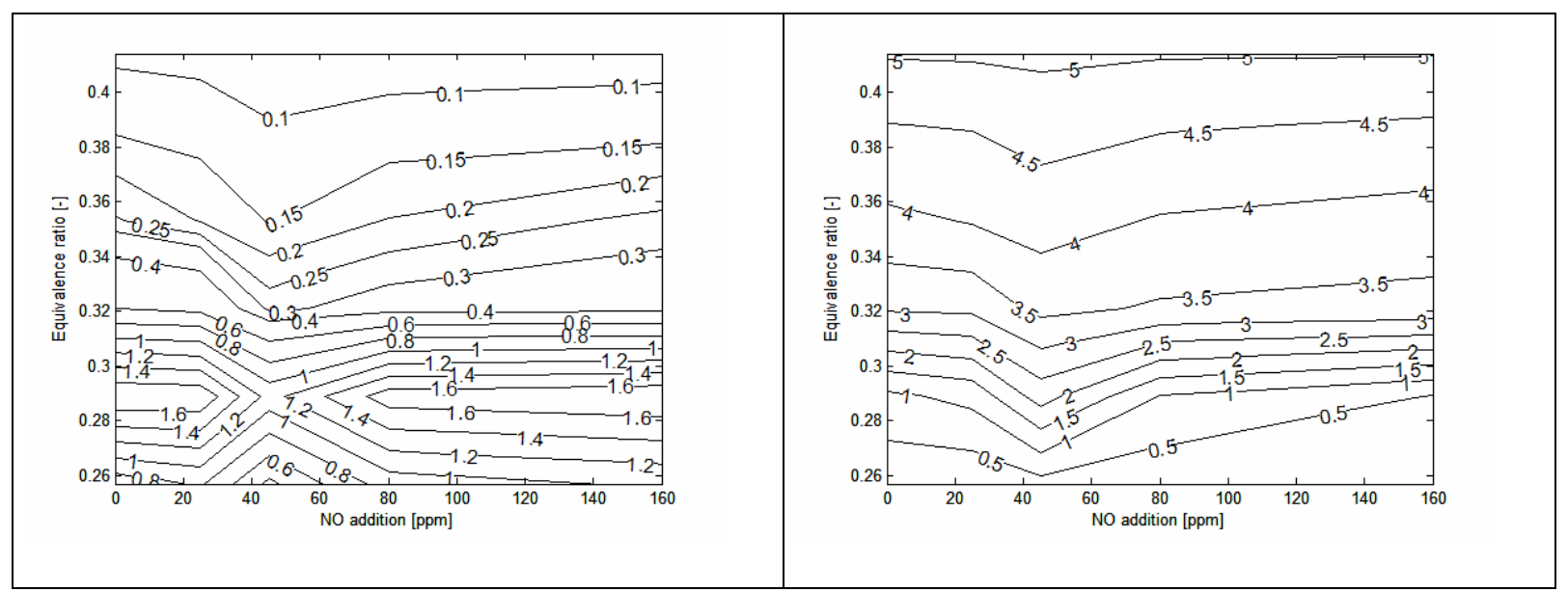

Figure 5: Iso-emissions of hydrocarbons (top-left), oxygen (top-right), CO (bottom-left) and $\mathrm{CO}_{2}$ (bottom-right) as a function of the added percentage $\mathrm{NO}$ in the inlet mixture and the equivalence ratio at an inlet temperature of $70^{\circ} \mathrm{C}$ and a compression ratio of 10.2 for the fuel "60 vol\% n-heptane and 40 vol\% iso-octane"

Figure 5 shows that NO first decreases the emission of hydrocarbons and then increases it. The interaction between NO and hydrocarbons has been subject to some study [19-21]. Faravelli et al. [22] explain the effect of the addition of NO to hydrocarbons on the ignition delay and thus the reactivity of the system. $\mathrm{NO}$ has the ability to activate $\mathrm{HO}_{2}$ radicals in $\mathrm{OH}$ : $\mathrm{HO}_{2}+\mathrm{NO}=\mathrm{OH}+\mathrm{NO}_{2}$

This reaction creates very reactive $\mathrm{OH}$ radicals, which increase the overall reactivity when they consume the fuel $[\mathbf{2 2 , 2 3 ]}$. However, excessive amounts of NO inhibit the oxidation at low and intermediate temperatures, because of the scavenging of $\mathrm{OH}$ radicals by the reactions

\section{$[24,25]:$}

$\mathrm{NO}+\mathrm{OH}+[\mathrm{M}]=\mathrm{HONO}+[\mathrm{M}]$

When the $[\mathrm{NO}]$ is such that the ratio of the reaction rates of "NO$+\mathrm{OH}$ " and "fuel $+\mathrm{OH}$ " becomes slightly greater than one, the system's reactivity drops sharply and the NO addition becomes thus an inhibition. The reactivity increase or decrease caused by the initial NO concentration is directly linked with the emissions. A higher reactivity means that more 
hydrocarbons are burned and a lower reactivity means that fewer hydrocarbons are burned. The same minimum is observed for the oxygen concentration and for the same reasons. After this minimum the overall reactivity decreases, converting also less $\mathrm{CO}$ into $\mathrm{CO}_{2}$, having more $\mathrm{CO}$ in the emission. $\mathrm{CO}_{2}$ shows naturally the opposite trends. The last chemical additive that is used to investigate its influence on the emissions is formaldehyde, of which the results are presented in figure 6 .

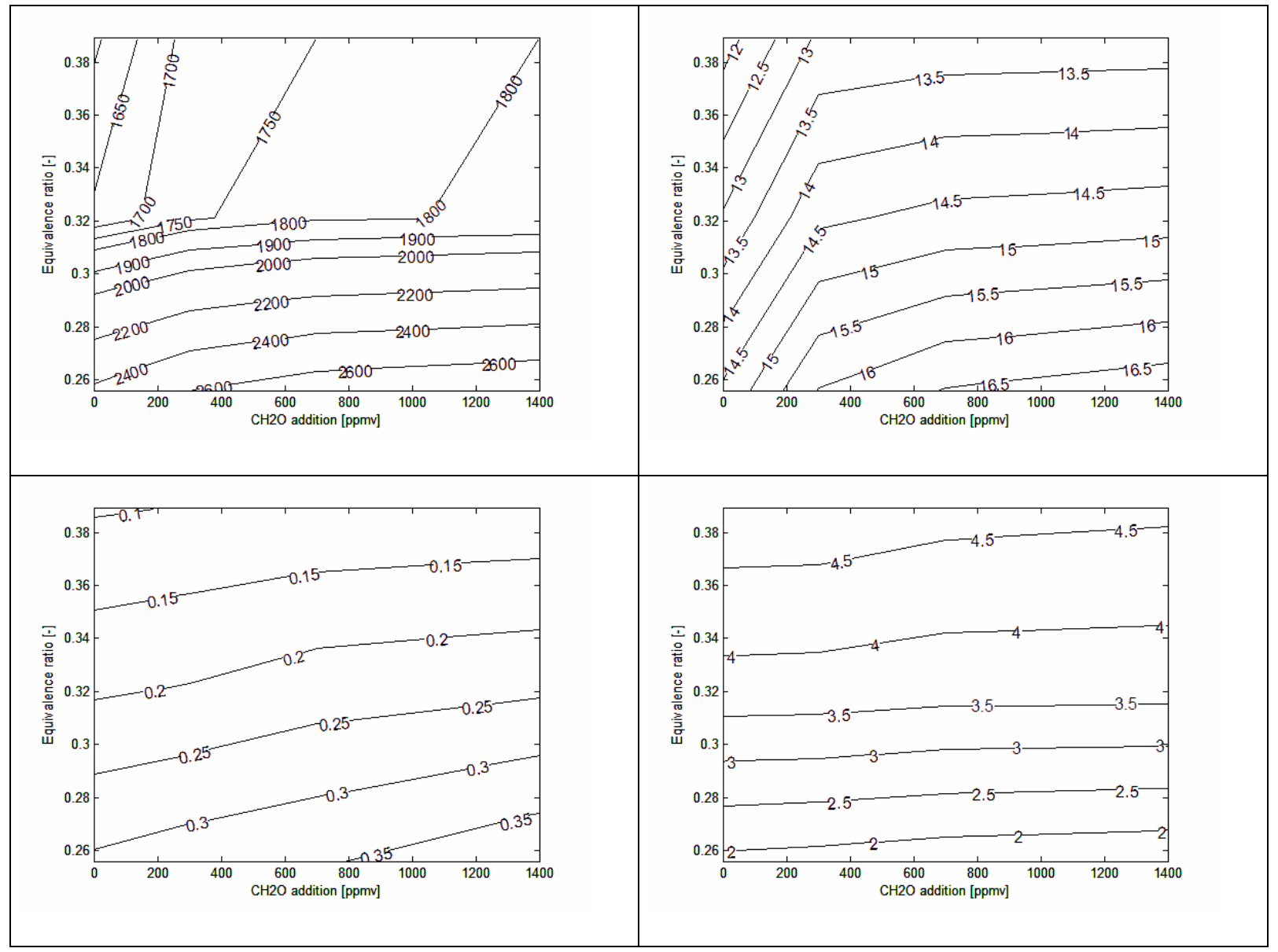

Figure 6: Iso-emissions of hydrocarbons (top-left), oxygen (top-right), CO (bottom-left) and $\mathrm{CO}_{2}$ (bottom-right) as a function of the added percentage $\mathrm{CH}_{2} \mathrm{O}$ in the inlet mixture and the equivalence ratio at an inlet temperature of $70^{\circ} \mathrm{C}$ and a compression ratio of 10.2 for the fuel "60 vol\% n-heptane and 40 vol\% iso-octane" 
An addition of formaldehyde increases, as figure 6 shows, the formation of hydrocarbons and of oxygen since formaldehyde consumes $\mathrm{OH}$ radicals and shares them with the fuel. This leaves less $\mathrm{OH}$ radicals for the fuel and decreases the overall reactivity. Therefore the peak temperature is attained later in the combustion cycle. Yamada et al. [26] explain this further. They state that formaldehyde shares the $\mathrm{OH}$ consumption with the fuel by the following reaction:

$\mathrm{H}_{2} \mathrm{CO}+\mathrm{OH} \rightarrow \mathrm{HCO}+\mathrm{H}_{2} \mathrm{O}$

$\mathrm{HCO}$ readily reacts with $\mathrm{O}_{2}$ to form $\mathrm{CO}$ and $\mathrm{HO}_{2}\left(\mathrm{HCO}+\mathrm{O}_{2} \rightarrow \mathrm{CO}+\mathrm{HO}_{2}\right)$. This reaction acts as a chain termination step. Thus fewer hydrocarbons are burned and less oxygen is consumed. Due to the decreased reactivity, more $\mathrm{CO}$ is formed, as is explained earlier in the text. The lower reactivity causes a lower peak temperature. This and the lower amount of $\mathrm{OH}$ radicals left, due to their reaction with formaldehyde, less $\mathrm{CO}$ is converted into $\mathrm{CO}_{2}$. Moreover, the reaction of formaldehyde with the $\mathrm{OH}$ radicals causes more $\mathrm{CO}$ to be formed.

\section{Conclusions}

First of all, it appears that reactivity is the key phenomenon. This implies that the emissions are not independent of the auto-ignition timing. From the results it appeared that increased reactivity decreased the emissions of $\mathrm{CO}$, oxygen and hydrocarbons at the expense of more $\mathrm{CO}_{2}$. The reactivity seemed to be increased by the equivalence ratio, the compression ratio, the inlet temperature, the EGR temperature, and the chemical species NO at low initial concentrations. However, when the initial concentration of NO became too high, the reactivity decreased. The addition of formaldehyde and the dilution by $\mathrm{N}_{2}$ also decreased the overall reactivity. The addition of the chemical species $\mathrm{CO}$ did not seem to influence significantly the overall reactivity. Furthermore it seemed that a fuel containing more iso-octane decreased the overall reactivity as well. These findings, however, did not appear to be valid all the time. It 
depended on the situation of the combustion and the indicated efficiency. The inlet temperature, for instance, did only influence significantly the emissions, when the combustion was not optimal (the indicated efficiency was not at its maximum). At maximum indicated efficiency, the inlet temperature had no more significant influence. The compression ratio only influenced significantly the emissions when a less reactive fuel was used, such as PRF40 versus $\mathrm{n}$-heptane. The influence of the equivalence ratio on the emissions of $\mathrm{CO}_{2}, \mathrm{O}_{2}$ and hydrocarbons is rather clear. A higher equivalence ratio results into a raised reactivity, which makes the emissions of $\mathrm{CO}_{2}$ increase and those of the hydrocarbons decrease, due to a better combustion. As far as it concerns $\mathrm{CO}$, it appeared that the equivalence ratio was a crucial parameter. A certain minimum equivalence ratio was needed in order for the system to have enough energy to convert $\mathrm{CO}$ into $\mathrm{CO}_{2}$. If this was not the case, a higher equivalence ratio will only increase the $\mathrm{CO}$ in the emission. It seems that the influences of the different parameters on the emissions are interrelated and that, indeed, the overall reactivity can explain most of the results. It is thus of great importance that whatever the conditions are, at which the HCCI engine should run, not only the indicated efficiency should be high (high power output), but the reactivity of the system should be high (lower emissions) as well. 


\section{References}

1 Machrafi, H., Development and experimental validation of kinetic schemes for hydrocarbon mixtures for HCCI applications. Investigation of the auto-ignition process and the application to internal combustion engines. $\mathrm{PhD}$ thesis, University Paris 6, 2006.

2 Lee, K., Lee, C., Ryu, J., Kim H., An Experimental Study on the Two-Stage Combustion Characteristics of a Direct-Injection-Type HCCI Engine, Energy Fuels; 2005, 19 (2), 393-402.

3 Sjöberg, M., Dec, J. E., Isolating the Effects of Fuel Chemistry on Combustion Phasing in an HCCI Engine and the Potential of Fuel Stratification for Ignition Control, SAE World Congress \& Exhibition, Detroit; 2004, SAE 2004-01-0557.

4 Christensen, M., Johansson, B., Supercharged Homogeneous Charge Compression Ignition (HCCI) with Exhaust Gas Recirculation and Pilot Fuel; 2000, SAE 2000-011835.

5 Bowman, C.T., Kinetics of Pollutant Formation and Destruction in Combustion, Prog. Energy Combustion Science; 1975, 1, 33-45.

6 Hyvonen, J., Haraldsson, G., Johansson, B., Operating Range in a Multi Cylinder HCCI Engine Using Variable Compression Ratio; 2003, SAE 2003-01-1829.

7 Flowers, D., Aceves, S., Westbrook, C.K., Smith, R., Dibble, R., Detailed Chemical Kinetic Simulation of Natural Gas HCCI Combustion: Gas Composition Effects and Investigation of Control Strategies, Journal of Engineering for Gas Turbines and Power; 2001, 123, p. 433.

8 Sullivan, J.L., Baker, R.E., Boyer, B.A., Hammerle, R.H., Kenney, T.E., Muniz, L., Wallington, T.J., $\mathrm{CO}_{2}$ Emission Benefit of Diesel (versus Gasoline) Powered Vehicles, Environ. Sci. Technol.; 2004, 38 (12), 3217-3223. 
9 Prucz, J.C., Clark, N.N., Gautam, M., Lyons, D.W., Exhaust Emissions from Engines of the Detroit Diesel Corporation in Transit Buses: A Decade of Trends, Environ. Sci. Technol.; 2001, 35 (9), 1755-1764.

10 Gabele, P.A., Pyle, S.M., Emissions from Two Outboard Engines Operating on Reformulated Gasoline Containing MTBE, Environ. Sci. Technol.; 2000, 34 (3), 368372.

11 Wu, C.-W., Chen, R.-H., Pu, J.-Y., Lin, T.-H., The influence of air-fuel ratio on engine performance and pollutant emission of an SI engine using ethanol-gasoline-blended fuels; Atmospheric Environment, 2004, 38, 7093-7100.

12 Fujimoto, H.G., Senda, J., Ito, T., Asao, S., Higashi, K., Characteristics of Intermediate Products Generated During Diesel Combustion by Means of Total Gas Sampling, SAE International, Powertrain \& Fluid Systems Conference \& Exhibition; 2004, 2004-01-2923.

13 Flowers, D., Aceves, S.M., Marinez-Frias, J., Smith, J.R., Au, M., Girard, J., Dibble, R., Operation of a four-cylinder 1.9L propane fueled homogeneous charge compression ignition engine : basic operating characteristics and cylinder-to-cylinder effects 2001 SAE 2001-01-1895

14 Sjöberg, M., Dec, J.E., Combined Effects of Fuel-Type and Engine Speed on Intake Temperature Requirements and Completeness of Bulk-Gas Reactions for HCCI Combustion, SAE; 2003, 2003-01-3173.

15 Flowers, D., Aceves, S., Smith, R., Torres, J., Girard, J., Dibble, R., HCCI in a CFR Engine: Experiments and Detailed Kinetic Modeling, SAE International, SAE World Congress; 2000, 2000-01-0328.

16 Lü, X., Chen, W., Huang, Z.A., A fundamental study on the control of the HCCI combustion and emissions by fuel design concept combined with controllable EGR. 
Part 1. The basic characteristics of the HCCI combustion, Fuel; 2005, 84 (9), 10741083.

17 Lü, X., Chen, W., Huang, Z.A., A fundamental study on the control of the HCCI combustion and emissions by fuel design concept combined with controllable EGR. Part 2. Effect of operating conditions and EGR on HCCI combustion, Fuel; 2005, 84 (9), 1084-1092.

18 Tanaka, S., Ayala, F., Keck, J.C., Heywood, J.B., Two-stage ignition in HCCI combustion and HCCI control by fuels and additives, Combustion and Flame; 2003, $132,219-239$.

19 Lavoie, G.A., Heywood, J.B., Keck, J.C., Experimental and Theoretical Investigation of Nitric Oxide Formation in Internal Combustion Engines, Combustion Science and Technology; 1970,1, 313-326.

20 Eng-Jr, J.A., Leppard, W.R., Najt, P.M., Dryer, F., The Interaction Between Nitric Oxide and Hydrocarbon Oxidation Chemistry in a Spark-Ignition Engine, International Fuels \& Lubricants Meeting \& Exposition, Tulsa; 1979, SAE 972889.

21 Yao, C., Cheung, C.S., Cheng, C., Wang, Y., Reduction of Smoke and $\mathrm{NO}_{\mathrm{x}}$ from Diesel Engines Using a Diesel/Methanol Compound Combustion System, Energy Fuels; 2007, 21 (2), $686-691$.

22 Faravelli, T., Frassoldati, A., Ranzi, E., Kinetic modeling of the interactions between NO and hydrocarbons in the oxidation of hydrocarbons at low temperatures, Combustion and Flame; 2003, 132, 188-207.

23 Frassoldati, A., Faravelli, T., Ranzi, E., Kinetic modeling of the interactions between NO and hydrocarbons at high temperature, Combustion and Flame; 2003, 135, 97-112. 
24 Mitchell, D.L., Pinson, J.A., Litzinger, T.A., The effects of simulated EGR via intake air dilution on combustion in an optically accessible DI diesel engine, SAE International, Fuels \& Lubricants Meeting \& Exhibition; 1993, SAE-932798.

25 Li, J., Chae, J.O., Park, S.B., Paik, H.J., Park, J.K., Jeong, Y.S., Lee, S.M., Choi, Y.J., Effect of intake composition on combustion and emission characteristics of DI diesel engine at high intake pressure, SAE International, International Congress \& Exposition; 1997, SAE-970322.

26 Yamada, H., Suzaki, K., Sakanashi, H., Choi, N., Tezaki, A., Kinetic measurements in homogeneous charge compression of dimethyl ether: role of intermediate formaldehyde controlling chain branching in the low-temperature oxidation mechanism, Combustion and Flame; 2005, 140, 24-33. 


\section{Figure captions}

Figure 1: Iso-emissions for the hydrocarbons as a function of the inlet temperature, the equivalence ratio, the fuel composition and the compression ratio for n-heptane. The figure at the bottom-right is with $60 \mathrm{vol} \%$ n-heptane and 40 vol\% iso-octane

Figure 2: Iso-emissions for $\mathrm{CO}$ as a function of the inlet temperature, the equivalence ratio, the fuel composition and the compression ratio for $n$-heptane. The figure at the bottom-right is with $60 \mathrm{vol} \%$ n-heptane and $40 \mathrm{vol} \%$ iso-octane

Figure 3: $\mathrm{CO}$ emissions and indicated efficiency as a function of the inlet temperature and the equivalence ratio with a compression ratio of 10.2 and PRF40 as the fuel

Figure 4: Iso-emissions for $\mathrm{CO}_{2}$ as a function of the inlet temperature, the equivalence ratio, the fuel composition and the compression ratio for $n$-heptane. The figure at the bottom-right is with $60 \mathrm{vol} \%$ n-heptane and 40 vol\% iso-octane

Figure 5: Iso-emissions of hydrocarbons (top-left), oxygen (top-right), CO (bottom-left) and $\mathrm{CO}_{2}$ (bottom-right) as a function of the added percentage $\mathrm{NO}$ in the inlet mixture and the equivalence ratio at an inlet temperature of $70^{\circ} \mathrm{C}$ and a compression ratio of 10.2 for the fuel "60 vol\% n-heptane and 40 vol\% iso-octane"

Figure 6: Iso-emissions of hydrocarbons (top-left), oxygen (top-right), CO (bottom-left) and $\mathrm{CO}_{2}$ (bottom-right) as a function of the added percentage $\mathrm{CH}_{2} \mathrm{O}$ in the inlet mixture and the equivalence ratio at an inlet temperature of $70{ }^{\circ} \mathrm{C}$ and a compression ratio of 10.2 for the fuel "60 vol\% n-heptane and 40 vol\% iso-octane" 